\title{
LOCUCIONS VERBALS I INTEL·LECCIÓ DE CLÀSSICS ROMÀNICS MEDIEVALS EN LES SEUES TRADUCCIONS. LOCUCIONS I COL·LOCACIONS MULTILINGÜES
}

\author{
Vicent Martines Peres \\ Institut Interuniversitari de Filologia Valenciana \\ Universitat d'Alacant \\ martines@ua.cs
}

\begin{abstract}
Resumen
'The aim of this essay is to present some of the results arising from the analysis of Ausiàs March's poems (source text) taking as a starting point the contrast between its several English translations from the $X X^{\text {th }}$ century.

This technique provides us with models to solve critical units of translation which are also «critical units» for the comprehension and reception of the source text. All in all, translation is the best and hardest way to prove the comprehension of literary works, even more when we are dealing with the works of an author with a difficult and sometimes brusque expression such as Ausiàs March.

In this piece of work we will present some examples of the contrastive analysis of the English translation of Ausiàs March's verses containing collocations, locutions and proverbs. Besides the inherent difficulty to translate them, these verses can provide us with a model to solve problems related to the current model of the standard Catalan language.

Thercfore, this is an interdisciplinary research that combines both elements of history of literature, of translation and of translatology (to check and prove the several techniques and translation criteria of English translators of Ausiàs March), and also elements of linguistics applied to discourse analysis (locutions, collocations and proverbs).
\end{abstract}

\section{IN'RODUCCIÓ}

L'anàlisi de les traduccions de què ha estat objecte una obra ens pot fornir de dades molt interessants des del punt de vista literari (evolució i extensió de les idees literàries, per exemple), així com també lingüístiques. Això ja ho he posat en pràctica quant al Tirant lo Blanch i les seues traduccions anteriors al segle XIX (MARTINES, 1997).

He desenvolupat aquesta línia de recerca i l'he aplicada a un altre dels nostres clàssics que, com ara Ausiàs March, han estat objecte de força trasllat al llarg de la història. ${ }^{1}$ De fet,

1 Vicent Martines, Ausiàs March "poligtota". El lexic d'ausiàs March a través de les seues traduccions des del segle XVI al XX a l'alemany, a l'angles, a l'espanyol, al francés $i$ a l'alemany. Concordances completes acarades, recerca patrocinada per la Conselleria de Cultura, Lducació i Ciència de la Generalitat Valenciana (Pla Estudis sobre el Valencià Actual), 2000; i El lexic d'Ausiàs March a través de les seues traduccions dels segles XVI-XX (a l'espanyol, a l'anglés, a l'alemany, a l'italià i al francés). Lematizacions completes acarades, recerca patrocinada per la Conselleria de Cultura, Educació i Ciència de la Generalitat Valenciana (Pla Estudis sobre el Valencià Actual), 2002. 
Ausiàs March, així com també Tirant lo Blanch, ofereix molt bones condicions en aquest sentit: nombroses versions (completes i fragmentàries de divers abast, des d'una sola poesia a versions de l'obra completa); nombroses llengües (cn: alemany, anglés, espanyol, esperant, francés, hongarés, italià, neerlandés); hi ha hagut versions de manera —-durativa—, és a dir, al llarg de diversos segles (XVI-XX); hi ha diverses versions en una mateixa llengua nombroses llengües; $i$, finalment, $h$ ha diverses tota una diversificada tipologia de traduccions, des de poètiques fins a les glosses en prosa).

Es tracta d'una metodologia interdisciplinar i que té uns objectius que, tot $\mathbf{i}$ concretats quant a Ausiàs March, poden ser fàcilment extrapolables i adaptables a altres autors que, en general, presenten unes condicions semblants a les que hem exposat anteriorment. ${ }^{2}$ Aquesta mena d'estudis poliglotes ens poden aportar a un coneixement més sòlid i fonamentat (contrastiu poliglota, diacrònic i sincrònic) de la història de la llengua de què es tracte. D'altra banda, poden fer possible l'estudi exhaustiu del lèxic de l'autor de què es tracte, de la seua fixació gràfica $i$ de la seua càrrega semàntica, tot establint una perspectiva contrastada amb el lèxic d'altres autors coetanis. Finalment, ens poden oferir un referents històrics o clàssics (antics o també moderns) útils per a l'enriquiment de la coneixença de la teoria i praxi de la traducció.

En aquest treball fem atenció a l'autor que ens ocupa i a la misció cntre Filologia i Traducció per poder bastir-nos d'eines que ens permeten ampliar la nostra coneixença del 1lenguatge poètic d'un clàssic romànic i europeu com Ausiàs March. En aquest sentit, hem de declarar que ens situem al recer del la intuïció ---al nostre albir genial - del mestre Martí de Riquer i de la immensa tasca realizada per ell sobre el particular. Ara podem fer nostres els seus mots quant a les traduccions castellanes d'Ausiàs March en «la Edad de Oro» $\mathbf{i}$ amb les quals obríem el nostre estudi, ${ }^{3}$ precisament quan justifica perquè les publica aplegades en un sol volum (RIQUER, 1946: viII):

\begin{abstract}
Al publicar íntegras cuatro traducciones castellanas de Ausiàs March [...], no pretendo que tales textos puedan substituir la lectura directa del gran poeta valenciano cuando se trate de conocer su obra, estudiarla o sencillamente entregarse a su paladeo. Agrupo estas versiones con lia finalidad de que podamos disponer facilmente de una base que nos permita estudiar la extensión y la intensidad que tuvo la influencia de Ausiảs March en la poesía española de los mejores tiempos. [...] Evidentemente, en cierta medida el procedimiento és válido, pues muchos ingenios castellanos leyeron a Ausias March directamente; pero se llegaba a cierto punto en el que era difícil determinar este aspecto, pucs otros, no conocedores de la que entonces denominaban «lengua lemosina», por fuerza tuvieron que recurrir a versiones castcllanas, las de Baltasar de Romaní y Jorge de Montemayor principalmente. En cualquier otro poeta es fácil, en casos parecidos, prescindir del vehículo intermedio;
\end{abstract}

\footnotetext{
Aquest treball és també un dels resultats del que va constituir la segona tesi doctoral de qui subscriu, en aquest cas, en Traducció i Interpretació i amb Menció de Doctor Europeu: Les traduccions de les poesies a'Ausiàs March a l'anglés. Eines per a l'estudi del llenguatge poètic d'Ausiàs March i de les seues relacions romàniques a partir de les seues traduccions angleses del segle XX, sota la direcció del Prof. Dr. Víctor Manucl Pina Mcdina (Programa de Doctorat en Traducció i Interpretació de Llenguatges Generals, Literaris i Especifics - Anglés-), Universitat d'Alacant, 2003 i que va meréixer la qualificació d'Excel'lent cum laude per unanimitat

2 De fct, ja ho aplique a altres autors nostrats medievals j del Renaixement.

3 Es tracta de les traduccions castellanes fetes, amb criteris diversos i amb nombre molt divers de poemes traduïts en cada cas, per Baltasar de Romaní, Jorge de Montemayor, Quevedo, l'anònim de El Escorial i el Brocense (SANTANACH \& MARTINH:S, 2000).
} 
pero en Ausiàs March ello es imposible. El poeta valenciano es, evidentemente, un autor de dificil lectura y cuya interpretación dista mucho de ser tarea sencilla. Los traductorcs han hallado en todo tiempo escollos durísimos e incluso dificultades de ciomprensión gramatical, lo qual, si modernamente puede salvar-se gracias a los adelantos de la filología, antes contribuyó a aumentar la fama de poeta que se dió a Ausias March.

\section{LA tRADUCCIÓ I LA TRADUCTOLOGIA AL SERVEI DE LA FILOLOGIA ROMANNICA}

Costanzo Di Girolamo, un filòleg de gran solvència i també traductor ben encertat d'Ausiàs March, iniciava un article exegètic seu subre Ausiàs March fet a partir d'haver de traslladar a la llengua de Dante declarant, quasi en to de màxima: «Per l'interpretazione di un poeta, Ia traduzione è certamente il più difficile banco di prova» (Di GrRoLAMO, 1997: 369). La traducció i la Traductologia poden ser magnífiques ocasions per a l'ensenyament de la literatura i per transmetre tot allò que conté l'obra o obres objecte d'atenció, des de la llengua a la contextualització històrica.

Shoaf cns glossa els guanys que aporta la traducció com a exercici per a la comprensió literària, textual i la millora lingüística —a més, de la millora quant a la pràctica de la traducció mateixa-. Ens explica com ha resolt, amb el "mètode tradutològic», les dificultats que tenia per entendre un passatge del Trolius and Criseyde de Chaucer —en concret els vv. 1386-1398 - en el qual hi havia un joc de paraules ( $p u n$ ) que se li resistia per a un estudi literari i per a unes classes que havia d'impartir sobre això a la seua University of Rochester. Ho va resoldre en traduir-ho (SHOAF, 1997: 80 i 87):

«To teach the pun in this passage (and in effect I have just taught it), I have had to be a better translator than the narrator. I have had to be more like the translator the narrator becomes at poem's end. I have had, in short, to read as if I were a writer translating the original into a different language (although not necessarily into a different tongue) and translating it with complete consciousness that I was transforming it in the process. I have had, in effect, to assume responsibility for the original as if it were mine (though, of course, it is not mine, strictly speaking). And this could do, and did so, only with a theory of translation as the loss of fullness and presence. To have taught the text otherwise would haven been to presume, as did the narrator, an innocent instrumentality and a transparency of history -it would have been, in effect, to be hopelessly naïve. But the teacher cannot afford such naivcté (especially the modern teacher of medieval studies). Every reader, in fact, from the bcginning student to the seasoned professional, is also a writer, or more accurately, a rewriter-and must be aware of that.

[...]

Reading and translating are not passive and receptive, but aggressive, contending, contextual, mutually assimilative - students come cventually to speak the text and, as we say, speak it as their own. The text is still Joyce's or Chaucer's or Virgil's, or the Beowulf poet's, but only in the context and the contest of the student's translation, itself transacted in the context and the contest of the tradition of the text's translation.»

No és una pràctica novella. S'arrcla cn una antiga tradició didàctica que, en l'àmbit anglosaxó té un intens conreu, en forma de l'anomenada «crossing translation» i, de fet, té fonaments molt més antics, ja en els estudis universitaris medievals i, especialment, en els Studia Humanitatis, clau de l'embranzidáa «filològica» de l'Humanisme. També té una 
intensa relació amb l'acarament de texlos, el que anomenem «textos paral·lels», que pot tenir magnífics rendiments didàctics i de recerca (Rino \& EerikäJnen, 1993; Nadal \& Prats, 1996: 130-150, 156-168, 204-208; COPLLAND, 1995; CRANZ \& KRISTELLER, 1976-1980).

Ja ens ho va mostrar, fa temps, un clàssic com ara don Enrique de Villena. En la seua Exposición del soneto de Petrarca (CÁTEDRA (ed.), 1994-2001: 1, 371-379; CÁltedra, 2002). Amb la traducció de l'original prèvia a l'elaboració del comentari, aquesta exposición és tot un intent per entendre i fer entendre el contingut d'aquesta composició, la qual pot esdevenir un epitom de la concepció que Petrarca mateix tenia de la literatura.

L'estudi de les traduccions obra d'autors hispànics medievals i del Renaixement pot ser ben instructiu sobre les seucs cstratègies compositives generals, així com també per fer una mica més de llum sobre els mecanismes estilístics concrets que hi feien servir, sobre la manera com reutilitzaven, traduïen o simplement traslladaven de context $\mathrm{i}$ de cotext les obres (completes) o els llenços o les llesques de text que traduïen. En definitiva, la Traductologia ens pot aportar cabals d'informació que ens permeten conéixer millor de quina manera componien i redactaven aqueixos autors $i$, a més, fer-ho amb perspectiva comparatista $i$, en el nostre afany concret, romànic (BUTTERWORTH, 1994: 19-35; KELLY, 1990: 399-873; GARCíA GABALDÓN, 1996: 126).

3. Una mostra: la praxi traductologica dels traductors anglesos d'Ausias March. TraDUCCIÓ 1 FILOLOGIA APLICADA

\subsection{Tècniques i criteris de traducció, eleccions lingüístiques: locucions i col·locacions}

En la bibliografia s'bre Ausiàs March podem comprovar que les traduccions han estat, després dels comentaris de poemes, un dels ítems que més nombre d'atencions ha tingut per part de la crítica. És una conseqüència lògica de la necessitat d'haver d'entendre Allsiàs March, els trets del seu llenguatge poètic, sobretot des d'una perspectiva específica $i$ ja no tant amb un abast o un enfocament textual —com ara els comentaris de pocmes-, sinó detallat. Convé - hi cal - tenir una mena de topografia detallada dels «accidents» de la superfície poètica del nostre autor a fi de detectar els nusos de força que ens permeten realitzar tasts de nivell profund en els hipocentres.

No volem abusar d'aquesta metàfora tectònica i, per tant, remetem a la tasca de qui ens han precedit. Hauf (1983) va ser el primer a fixar-s'hi, en la imperiosa necessitat de conéixer al detall -al màxim, fent atenció a les unitats lèxiques bàsiques, els mots- els elements de construcció de l'edifici poètic de March. En aquest treball nostrc, pretenem, com ja hem establert, scrvir-nos de les traduccions - moltes elles realitzades per filòlegs medievalistes de reconegut prestigi $i$, en general, per grans coneixedors de les llengües a les quals traduïen [sobretot les angleses, la italiana, la francesa, així com també l'alemanya; quant a les espanyoles] — per contribuir a entendre l'original.

I ho és perquè en traduir hem de tenir present els mots i les seues xarxes d'interdependències sintàctiques i semàntiques. Per això, en aquest treball, ${ }^{4}$ establim una edició interlinial interversal- de l'original i les seues traduccions. Així serà molt més fàcil poder passar a

4 En altres llocs hem establert les concordances, el llistat de mots de cada traducció i les lematitzacions completes de les traduccions, acarades entre si i acarables a les de l'original. 
un anàlisi del llenguatge poètic que contemple com a referent, no només les unitats lèxiques bàsiques, sinó també les solidaritats lexicosemàntiques que s’hi estableixen.

Així tindrem els elements per poder calibrar amb detall les clàusules de compromís morfosintàctic i semàntic d'abast sintagmàtic i realitzar anàlisis de cas quant a kentorns» 0 atributs essencials per a la caracterització - i la comprensió o inintel-lecció- del llenguatge poètic del nostre autor. Per una banda, les uocucions - especialment les verbals, atés la seua influència en l'oració $i$ tenint en compte que tractem amb un poeta com ara March, tendent cap al caragolament sintàctic-. Les locucions són elements essencials a l'hora de caracteritzar, en filologia, l'estil d'un autor (MALMKJAER, 1993) i, en traductologia, haver de «naturalitzar» el text meta (LozAno GonzÁlEZ, 1992). D'altra banda, les CoL-LOCACIONS (o solidaritats lèxiques) (BEEKMAN, 1991 [1992]; BENNETT, 1994) i, finalment, els elements de fraseologia (Pavfl, 1995) o d'afortsmes o de parèmia (NüÑez García, 1999; Ojanguren FERNÁNuĽ, 1995 (1997); NiKoláEva, 1997).

Tot plegat es tracta de «clixés» que determinen l'establiment d'uns criteris d'actuació en haver-los de traduir que han de formar part de l'estratègia traductològica (ANTOINE, 2001; Cantera Ortiz de Urbina, 2000), precisament perquè poden ser elements que indiviuen ja l'original, que l'ancoren en un tempo lingüístic $i$ en una mena literària concrets. Es tracta de conceptes de gran densitat epistemològica quant als paradigmes de la lingüísctica (FAwCETT, 1997). Cal comprovar quan es resolen amb transposicions, modulacions, equivalència o adaptacions (BAKER, 1992). Fins $\mathrm{i}$ tot pot ser ben interessant això com a escandall en l'establiment de les modalitats estàndards, des del punt de vista de les aplicacions de la traducció més enllà del «mer» trasilat de textos o discursos concrets; a més, si calgués cercar d'una altra aplicabilitat per a la traducció, en l'ensenyament de llengües (FonTENELLE, 1994; Heliel, 1990; HJorNaGer, 1985 [1986]). Atcndre a tots aquests elements, en aquest epígraf $i$, in extensu, en l'eđició interlinial, ens pot donar les eines per constituir de fet un corpus ausiasmarquià, parallel, interlinial i multilingüe (l'original i les diverses traduccions): un veritable corpus literari i lingüístic (KENNY, 2000, 2001; VINTAR, 2001; CORPAS PAS'IOR, 2000; Dobrovol'skit, 1990 [1992]; Fernández GonZÁlez, 1995).

Aquests elements són essencials per entendre la construcció d'un text (des de la retòrica lingüística, la lexicografia, lexicografia o sintaxi (Peters, 1992; Mayoralas, 2000)), sia des de la perspectiva de l'anàlisi del discurs original, sia des de la perspectiva traductològica específicament (WILSS, 1997; NAVARRO, 1995 [1996]: $\$ \S 9,11,14$ ).

Hi ha, altrament, interés des del punt de vista de la diversa activació dels procediments de mctaforització (GÉNIN, 2001; FUERTES \& SAMANIEGO, 1998), com a qüestió «centaure» entre aspectes pròpiament filològics i uns altres de culturals (MITJA, 1989; MoESCHLER, 1991 [1992]), més encara quant a originals medievals, evidentment allunyats del traductor tant en el vector diacrònic, com ara quant a l'estat de llengua o a la visió de món (BARBoLANI di Montauto, 1997; Hosington, 1993 [1996]; ARrimadas, 1987). Per tot això són veritables «unitats crítiques» de traducció que determinen haver de realitzar transposicions, modulacions, equivalències o adaptacions (García Izoquierdo, 2000; Salvador \& Piquer, 2000; FraILE, 2001) i això vol dir que el traductor ha hagut d'entendre ben bé l'original. Això és el que ens pot mostrar el camí a seguir per acabar d'entendre Ausiàs March.

En gran part, potser la problemàtica d'aquestes unitats provinga del fet d'estar profundament arrelades en el context lingüistic i cultural (Gargallo Gil, 2002; Amossy, 2001; BEHIELS, 1993); i per això n'hi haja tants casos intraduibles i que s'hagen de resoldre a través 
d'adaptacions o d'equivalèncics (COMBeT \& Sevilla MUÑoz, 1995) i que, per això mateix constituïsquen camps de lliça de la lingüística cognitiva i de l'anàlisi contrastiva (CuENCA, 2000; FABREgat, 1994 [1997]) i de l'exègesi literària (rcferències citades a peu de pàgina $\mathrm{i}$ referides als versos corresponents, pel que fa en el nostre cas a Ausiàs March).

En cada unitat d'anàlisi, l'estructura interversal serà la següent:

- primer, l'original d'Ausiàs March $(<0>$ ), que conté totes les referències a les variants detectades en els diversos trasllats que en cada cas n'hi haja;

- després, la versió d' $\Lambda$ rthur Terry ( $<T E \gg$ ), que sols conté les referències a les variants que ella manifesta respecte a l'original - marcades convencionalment amb «( )» $\mathrm{i}$ l'exponent que hi correspon a fi de facilitar-ne la localizació-;

- després, la versió de Conejero-Ribes-Keown ( «<CO>»), que sols conté les referències a lcs variants que ella manifesta respecte a l'original - marcades convencionalment amb «[ ] i l'exponent que hi correspon a fi de facilitar-ne la localització-;

- després, la versió d'Archer ( $\langle\mathrm{AR}\rangle$ ), que sols conté les referències a les variants que ella manifesta respecte a l'original - marcades convencionalment amb $《 / \gg \mathrm{i}$ l'exponent que hi correspon a fi de facilitar-ne la localització-;

- i, finalment, quant al poema 28 , les corresponents a la versió que Curt Wittlin en va fer $(<W I>)$-marcades convencionalment amb «<> $>$ i l'exponent que hi correspon a fi de facilitar-ne la localització-s

Aquest mètode, que ja ja vam presentar quant a Questa del Sant Grasal catalana (1380) respecte la Queste del Saint Graal francesa original (primer terç del segle XIII) (MARTINEs, 1995 i 1996) i quant al Tirant lo Blanch i les seues traduccions italiana, espanyola i francesa dels segles XVI-XVIII (MARTINEs, 1997), resulta, almonys, pràctic, atés que facilita la localització i la caracterització de les variants que detectem en cada cas. Cada anàlisi interlinial específica va seguida d'un cos de notes en les quals analitzem o expliquem les variants.

No provem de fer cap recensió de les traduccions de referència, ni tampoc despullar-ne les gràcies ni les desgràcies. En la immensa majoria dels casos, els traductors encerten en les scues versions $\mathrm{i}$ en funció dels objectius que en cada cas s'havien plantejat -i expliciten en les introduccions respectives-. Potser, la millor ubicació de cadascuna de les tres versions angleses principals dels poemes d'Ausiàs March (cronològicament: Terry, Conejero-RibesKeown, i ARCHFr -a més a més de Wittlin, quant al poema 28-) i de la «funcionalitat» de cadascuna, la tínguem en el paràgraf següent, extret de la ressenya que Terry va fer de la versió d'Archer:

«Thus he [Archer] steers a middle course between my own versions - now, alas, out of print - which were meant chiefly as an aid to rcading the original texts, and the somewhat archaic verse translations of Concjero, Ribes and Keown. The results, to my mind, are remarkably successful: though they often deliberately avoid the tortuous syntax of the originals - surely part of the experience of reading March-they are attractive to read, and, where necessary, help to clarify the subtle twists of March's thought (and, since all translation involves interpretation, it is here that one reaps the benefit of Archer's long and profound acquaintance with these poems).\%

5 Així mateix, per facilitar la localització de les variants traductològiques que afecten especificament les locucions, els aforismes $i$ els elements de parèmia, $i$ les collocacions, les consigne en cursiva. 
Així, aquestes tres versions configuren sengles vèrtexs quant a la concepció i praxi traductològiques i la manera d'abordar el trasllat dels clàssics --interpretació literària-. Conejero-Ribes-Keown clouen la introducció de la seua traducció (en la reedició de 1997. 2001: XXXIII) així:

The present translation contains 74 pocms which have already been published in three separate volumes (volume 1, 1986; volume II, 1989; volumne III, 1993). It is in verse form and it tries to respect March's style, characterized by numerous cllipses, torturous syntax, linguistic ambiguities, which at times may leave the reader somewhat disconcerted. It is precisely this impression - the same one experienced by a native reader - that we have attempted to convey in our translation.

Aquí es contenen les coordenades essencials de les tècniques que segueixen aquests traductors pel que a Ausiàs March: transposicions (sovint abruptes); modulacions semàntiques i sintàctiques (sovint incrementatives i molt poques vegades reduccionistes) que tendeixen a conferir, en general, un to més intensiu a la traducció; tria lèxica i la textura morfosintàctica que tendeix a ser més arcaïtzant que les de Terry o la d'Archer.

Dominic Keown ens ofereix un magnífic resum sobre les ets i les uts del mètode posat en pràctica en la seua traducció, l'única - ben cert- que ha provat i no sence encert traslladar Ausiàs March a l'anglés en vers (KEown, 1999). De fet, es van plantejar la qüestió de si havien de presentar Ausiàs March en vers o en prosa i raona la decisió així, en relació a l'opció prèvia de Terry i a posterior d'Archer:

En la seua justament aclamada antologia bilingüe, Arthur Terry va optar per una transcripció no mètrica: un exemple seguit - no sense èxit-per Robert Archer. El fonament que hi ha al darrere d'aquesta tria és clar i convincent. S'ha de tenir en compte que una versió literal i rasa a la vora de l'original permet una comprensió completa i immediata. D'altra banda, el traductor no pot usurpar en cap moment l'ascendència establerta entre l'autor i la seua traducció. El lector és obligat a enfrontar-se amb l'original; la traducció queda en una posició de subordinació, scnsc cap aspiració de controlar o d'emular el seu model. [...] D'altra banda, no podem negar que molt de la intensitat implícita en l'estructura de la poesia s'esvaeix quan la rearrangem en prosa. (Keown, 1999: 202)

Al tall d'aquest fil d'argumentació continua fent referència més concreta a les raons que els va fer decidir pel seu mètode (KEown, 1999: 204):

Com a conseqüència -i açò era remarcable quant a Ausiàs March-, encara que tàcitament, en el procés de traducció vam haver d'assumir certes condicions prèvies. L'ideal d'equivalents de Schleiermacher, que cerca de proveir al lector estranger amb «the same image and the same pleasure as reading the work in the original language offers the man cducated in this way» [...]. No obstant, seria enginyós l'extrem d'imaginar qué el lector anglés actual podia acceptar amb diligència la llengua antiga i l'abstrusitat de l'embolicada introspecció de March. És ben sabut, per exemple, que fins i tot els estudiants de l'especialitat de Literatura Medieval recorren a versions actuals del en comparació transparent Chaucer abans que no esforçar-sc amb els delits de l'original. Com a resultat, el nostre esforç procurava inicialment de fer-ho més llegidor, potser fins i tot excessivament. L'acte de la lectura es facilitava amb una ortografia modernitzada, tot fent fora l'el-lipsi, tot actualitzant l'expressió i tot resolent parcialment les dificultat lingüístiques. 
Per compensar aquesta revisió, havíem de fer un «element estranger» mitjançant un arcaisme estrany. Ara, amb el benefici de la percepció retrospectiva, cada vegada que torne als nostres primeres assaigs, tendisc a percebre una mena d'inconscient inclinació a tornar a metre l'inveterat gandienc pcr a un consum modern: un intent de fer més coneguda la figura d'Ausiàs March tant com a traduir-lo.

Keown defensa aqueixa metodologia afirma, finalment (KEOwN, 1999: 204-205, 208 i 210):

En el cas de la nostra traducció en vers d'Ausiàs March, l'assumpte ambiental de la projecció i de l'assoliment del reconeixement exteriors va fer triar l'última alternativa: és a dir, facilitar la lectura al públic anglòfon actual. L'apropament alternatiu pot ser resumit per les arcanes traduccions de Pound a partir dcls mestres italians o, efectivament, la fidel austeritat de les versions cn prosa d'Arthur Terry, que forcen el lector a adreçar-se al poeta i a enfrontar-se amb l'atractiva dificultat de l'original. [204-20.5]

[...]

Tanmateix, a mesura que el projecte avançava, cada vegada era més evident que el fonamental de l'expressió de March era, precisament, la seua sintaxi inflexible i sovint arcana. En efecte, això és tant una part de la seua pròpia llengua com el seu voluntari antilirisme. $\Lambda \mathrm{ixj}$, es va fer més evident la necessitat de transmetre aquest tret estilístic en la traducció. $\mathrm{Hi}$ havia un valor afegit si adoptàvem aquest mètode: el manteniment de l'ordre sintàctic realment tendia a recordar més plenament l'original, tot intensificant el «tast estranger». [208]

[...]

No sorprendrà als que es dediquen a la perillosa tasca de la traducció - i especialment la del gran gandienc- que és precisament quarı Mírch és més accessible i viu per al lector valencià actual, que es troba més allunyat $i$ amagatper a l'anglòfon, pr la qual cosa podem considerat totalment legítimes les raons de transposició lírica. No és insafisfactori imaginar que la peculiaritat d'aquesta anomalia podria haver-se demostrat tot entretenint el nostre poeta i la seua celebrada preferència per la inescrutabilitat de l'enigma. [210]

En definitiva $\mathrm{i}$ com hem llegit que aquests traductors mateix ja declaren, aquesta versió no és feta per ser una crossa que ajude el lector perquè no «faça camins dubtosos en la mar» de versos d'Ausiàs March, com sí volia fer Terry en la seua. De fet, Conejero-RibesKeown volen «metre» Ausiàs March en «English verse». De fet, aquesta traducció és molt fidel i equivalent a l'original, i això és un mc̀rit d'aquests traductors. Aquesta versió és força «centrípeta». Ens pot remetre a la lírica isabelina anglesa (ss. XVI-XVII) i no és desgavellat dir-ne que vol encabir-se en un solc «shakesperarià». Això és lícit en traducció i ho fan així perquè pot ser un referent equiparable en l'àmbit cultural i líric anglés al que representa Ausiàs March en el català, hispànic i romànic. Això, pcrò, imposa que els seues «lectors (anglesos) hagen de saber molt d'anglés».

La traducció de Terry és centrífuga, vol ser un Mercuri que transmeta el text d'Ausiàs March. Alhora, no perd mai de vista l'original i només en molt comptades avinenteses podem dir que arribe a «cometre» adaptació —i menys encara adaptació per inintel-lecció-. De fet, quan ha de fer modulacions incrementatives lèxiques i afig o intepola mots —o poques voltes sintagmes -, ho consigna entre parèntesis.

Archer també aborda la seua traducció amb una perspectiva centrifuga tot i que més que no Terry; d'altra banda, Archer se situa en l'extrem oposat a Conejero-Ribes-Keown. De 
fet, la seua traducció, així com també la de Terry, és en prosa, tot i que es fàcil de fer-ne là correspondència amb l'estructura versal de l'original. ${ }^{6}$ Archer mateix ens diu en «A note on the Translation and Text) (ARCiER, 1992: 19):

Rather, I have tried to produce prose versions that I hope are readable and completely intelligible in themselves, without the aid of explanatory notes or close comparison with the text. At the same time, since March presents so many difficulties of interpretation, the translation also represents as unequivocal a statement as possible of how this translator interprets the poems.

This has sometimes meant including in the translation elements of meaning that $\mathbf{I}$ consider implicit in March's text and essential to its understanding. For the sake of clarity, I have changed where necessary the original (often challengingly complex) syntax or order of ideas. Occasional redundancies (sometimes introduced by March to resolve metrical problems) have been eliminated.

La mateixa estratègia ha estat en la base de la nova traducció de poemes d'Ausiàs March que ha acabat Archer. Al «Preface» d'aquesta traducció, tot just acabada de fer i encara inèdita, ${ }^{7}$ Archer reprodueix el primer paràgraf de la citació anterior. I afig tot seguit: «The aim of the present version remains largely the same (although some explanatory notes have been added).\$

Aquesta nova traducció, però, presenta diversos elements que la fan especialment interessant. Per una banda, n'hi ha fins a 55 poemes traduïts - la meitat més que en Archer, 1992 - ; d'altra banda, Archer indica que ha revisat les anteriors traduccions a la llum de la nova i nombrosa bibliografia ausiasmarquiana apareguda en els darrers anys i en la qual ell ha tingut una part significativament important atés que, entre altres estudis seus, ha estat l'autor d'una edició filològica de 1'original -que obtingué, a més, un premi de la Secció Filològica de l'Institut d'Estudis Catalans-. En aquest cas, les relacions cntre traducció i filològia són explícites i confirmen les paraules de Di Girolamo que hem reportat al començamcnt d'aquest epígraf. Archer ens ho explica en un paràgraf del «Preface» a la seua nova traducció (Archer, 2004 [en premsa, dins la Xarxa d'Excel-lència Europea «TRAMICTEK» - Translation, Multilingualism, Information and Communication Technologies and Transference of Knowledge'-]):

Since these words were written [es refereix les de la introducció d'Archer, 1992 que hem citat adés quant als criteris de traducció que hi va fer servir], however, a great deal has

6 Com hem tingut ocasió de comprovar en haver de fer la correspondència entre els trasllats en prosa de Terry i d'Archer i els originals en vers d'Ausiàs a fi d'aplicar el programa informàtic TrAMCltk-02, per establir l'cdició interlinial.

7 Agraïsc ben de cor a Robert Archer primer que haga coronat aquesta tasca tan necessària per a l'ampliació $i$ per a la millora del coneixement d'Ausiàs March i que, scgon, m'haja permés de fer-la servir en aquestes anàlisis, tot i que no hi ha hagut temps material per poder aplicar-li el programa TRAMCTEK-02 i incloure-la -com a primicia- en l'edició interlinial. De tota manera, atés que es tracta, aquest d'Archer, d'un treball rigurosament inèdit, no ens ha semblat del tot pertinent traure'l a llum en aquesta edició interversal abans que no hagués estat publicat com a l'obra unitària - i excel-lent- que és.

Això no obstant, sí que he tingut en compte les versos concrets que, en aquesta nova traducció, corresponien a poemes abans no traslladats per Archer o que, tot i haver-ho estat abans per ell, manifesten variants 0 esmenes. Citaré ARCHER, 2004 [en premsa]. En les anàlisis traductològiques, la referència a aquesta nova traducció d'Archer serà: « $\angle \mathrm{AR} 2>$ ». 
been published on Ausiàs March (inciuding the excellent Italian Translation of Costanzo Di Girolamo) and I have completed and published my own critical edition of March. Inevitably, during this period, I have come to interpret some of March's works in a way that is different from the one reflected in the 1998-1989 translations. At the same time, my concept of how a translation should work in relation to the source text has changed considerably, largely bccause I have had the opportunity to consider seriously issues of translation practice and theory in my teaching at Durham. All these factors have meant that the present versions aliffer frequently, and sometimes considerably, from those that were published in the Anglo-Catalan Society series.

Per la seua part Curt Wittlin, en el preàmbul a la seua versió «rítmica» del poema XXVIII d'Ausiàs March, ja ens explica alguns dels problemes i quines serien les dues solucions -no desproveïdes d'ironia- per tenir la traducció completa en anglés de les poesies d'Ausiàs March (Wittlin, 1999: 224-225):

Els traductors d'Ausiàs March provablement podrien aprofitar-se de la reflexió sobre la situació de lcs traduccions de Shakespeare. Una primera gran diferència, tanmateix, és de mena comercial. Shakespeare és prou famós arreu i pot fer vendre traduccions de les scues obres fầcilment per onsevulla, fins i tot a gent que immediatament les arrimaricn. March és molt menys anomenat. [...]

$[\ldots]$

Encara no tenin traduccions en anglés de tots cls poemes d'Ausiàs Marc. Moltes de les traduccions fetes de fa temps són cn prosa, i segueixen l'estil de les paràfrasis. Això permet traduccions explicativcs, justificades com a «ajuts perquè el lector estudie l'original en català». Aquestes versions, normalment més llargues que l'original, s'han hagut d'imprimir a línia tirada a fi d'evitar que s'assemblen a la poesia original. Ĺs sorprenent perquè hom no ha provat més sovint traduir Ausiàs March a l'anglés en versos rítmics o potser en rima. Què no creu ningú que March puga interessar a un nombre de lectors més gran, que s'interessen per altres temes, per altres llocs, pels sentiments d'una altra persona? $[\ldots][225]$

$[\ldots]$

Les traduccions d'Ausiàs March que m'agradaria veure se situen entre les versions que hom pot cantar amb la música escrita per a l'original i les traduccions filològiques que només aspiren a ser guies del text català. Sembla que hi cal la col laboració entre traductors solvents filològicament, un poeta (preferiblement famós) i un editor mamprenedor. $\mathrm{La}$ primera fase, és clar, és fer paràfrasis que siguen correctes en tos els detalls. A l'hora d'ara, hi ha qui té la preparació necessària per fer-les. Cadascú podria revisar la faena dels altres. El poeta de l'equip estudiaria totes aqueixes paràfrasis i faria la versió poètica. Els filòlegs entendrien si la versió poc̀tica fos massa allunyada de l'original, de tal manera que es fes dificil comparar temàticament els poemes corresponents.

Trobar un poeta així pot ser més dificil que no un editor ric. [226]

[...]

[Conclusions]

[...] N'hi ha poes que puguen reivindicar ser especialistes en Ausiàs March, però lots són crítics de traduccions, especialment de les poc̀tiques. La solució pot ser comptar amb un poeta famós, un de tan anomenat que es trobe per damunt de les crítiques, a l'hora de fer poemes de les paràfrasis dels filòlegs. Però sóc pessimista sobre el desenvolupament de la indispensable col-laboració entre poetes i ausiasmarquistes. [231] 
Així, podem calibrar ben bé la praxi traductològica dels traductors anglesos d'Ausiàs March es concreta en les nostres anàlisis fonamentades en les locucions verbals, els elements de parèmia $i$ les col locacions - $i$, a partir d'aquí és ben fàcil de veure-ho in extensu en l'edició interlinial- sovint podem observar elements de variació de registre lingüístic entre aquestes tres versions, que assenyalem on correspon (CORONFI, 1994-1995, i 1997). Aqueixos poden ser les millors conslatacions de les característiques de cada traducció i, alhora, la millor manera de diferenciar-les; d'altra banda, aqueixos casos esdevenen bons exemples des del punt de vista del variacionisme lingüístic. ${ }^{8}$

\subsection{Unitats crítiques d'acarament traductologic. Locucions verbals}

caure en dolor loc. verb. Experimeniar dolor.

Poema 16

V. 5

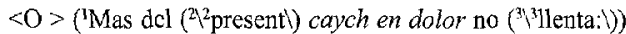

$\langle\mathrm{CO}\rangle$ ('But for the ('nonce) I fall in pain not ('slight:))

$<A R 2\rangle\left\langle{ }^{1} B\right.$ ut for the $\iota^{2}$ present $\left.a\right|^{3}$ sharp $|$ pain grips me $\backslash$

Notes:

(1) Modulació semàntica.

(2) Modulació lèxica; podem percebre una certa variació de registre respectc a $\^{2}$ i també respecte a l'original. De fet, ${ }^{2} \backslash$ és més fidel.

(3) Modulació lèxica.

$++$

V Modulació semàntica.

12 Modulació lèxica; podem percebre una certa variació de registre respecte a $\left(^{2}\right) \mathrm{i}$ també respecte a l'original. De fet, 12 és més fidel.

(3) Transposició i modulació lèxica.

complir desig loc. verh. Sutisfer la voluntat.

Poema $81^{9}$

V. 7

$<\mathrm{O}\rangle\left[{ }^{1}\left({ }^{1 / 1} /{ }^{1}\right.\right.$ esesperat $\left.\left./\right)\right]$ de $\left({ }^{2 / 2} /\right) \operatorname{mos}$ desigs $\left[{ }^{2}\left({ }^{3 / 3}\right.\right.$ complir,$\left.\left./\right)\right]$

$\langle\mathrm{TE}\rangle\left[{ }^{1}\right.$ Without hope] of $\mathrm{l}^{2}$ achieving] my desires,

$\langle\mathrm{CO}\rangle$ ('With hope all gone, ( ${ }^{2} \mathrm{e}$ 'er) ("io fulfill) my wishes,

$<\mathrm{AR}>/ \mathrm{In}$ despair/ $/$ of ever/ $/ \beta$ fulfiling/ my desires,

$<\mathrm{AR} 2>$ idem $<\mathrm{AR}>$

Notes:

['] Modulació sintàctica.

$\left[{ }^{2}\right]$ Literalitat lèxica; podem percebre una certa variació de registre respecte a $\left({ }^{3}\right)$ i a $/ 3 \%$.

$++$

(1) Modulació incrementativa sintàctica, que tendeix a fer més intens el passatge-vid. (2)-

(2) Modulació incrementativa sintàctica, que contribueix a intensificar més el passatge, en relació amb (').

Tot i que no és aquest l'objectiu del present treball.

Vid. els comentaris de Dilla, 1997 i ZMMMERMANN, 1997. 
$\left({ }^{3}\right)$ Modulació semàntica; podem percebre una certa variació de registre respecte a $\left[{ }^{2}\right] \mathrm{i}$ a $\beta \%$

$++$

11 Modulació semàntica.

2) Modulació incrementativa sintàctica - vid. $\left({ }^{2}\right)$ -

B) Modulació semàntica; podem percebre una certa variació de registre respecte a $\left[{ }^{2}\right] \mathrm{i}$ a $\left(^{3}\right)$

creure de cert loc. verb. Tenir la seguretat, estar segur d'alguna cosa.

Poema 90

V. 21

$<\mathrm{O}>\mathrm{e}$ ('crech de cert) ('ésser malventurós)

$\langle\mathrm{CO}\rangle$ ('Full sure $1 \mathrm{~cm}$ ) ('he's truly evil-starred)

Notes:

(i) Literalitat lèxica.

$\left({ }^{2}\right)$ Modulació incrementativa sintàctica. De fet «truly» estableix una modalització, alhora que fa més intens el passatge. D'altra banda, val a dir que «evil-starred» contribueix a remarcar el sentit «malaventurós» de l'original, amb allò que contć in origine de referència als fats, als astres.

dar fe loc. verb.

a) Certificar, acreditar.

Poema 20

V. 7

$<0>$ En vós és tot, e no $\mathrm{m}$ cal $\left({ }^{1} d a r-h i f e\right)$

$<\mathrm{CO}>$ In you all is, no need have I ('t'attest,

Notes:

(1) Litcralitat lèxica.

b) Comprometre la paraula, comprometre's, donar la paraula.

Poema $10^{10}$

V. 12

$\langle\mathrm{O}\rangle \quad\left[{ }^{\prime}\left({ }^{\prime}\right.\right.$ 'dant fe lo rey que [ ${ }^{2}$ bon compte-n retria $\left.]\right]\left[{ }^{2}\right]$

$\langle\mathrm{TE}\rangle \quad$ ['the king pledging himself [ ${ }^{2}$ to render good account $]\left[^{3} \mathrm{of}\right.$ them]

$\langle\mathrm{CO}\rangle \quad$ ('On the condition of good stewardship,)

$<A R 2>\quad V o n c e$ the king had sworn to be his vassal and to be answerable to him in matters concerning them

Notes:

[1] Transposició.

$\left.{ }^{2}\right]$ Literalitat lèxica.

[3] Modulació incrementativa sintàctica.

$++$

(1) Adaptació

$\because 1$

$M$ Adaptació.

10 Vid. els comentaris de PujoL, 1997. 
donar terme loc. verb. Donar fi.

Poema $13^{11}$

V. 32

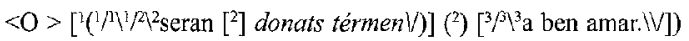

$\langle\mathrm{TE}\rangle \quad$ [1 there will [ ${ }^{2}$ also] be an end] to [ ${ }^{3}$ good loving.]

$\angle \mathrm{CO}>\quad$ ( ${ }^{3} \mathrm{Good}$ loving) ('then) ('will also have its close.)

$\quad\langle\mathrm{AR}>\quad /$ the $\beta$ love/ $/$ will have reached its limits.//

$<$ AR2 $>\quad V$ then $1^{3}$ true lovel $1^{2}$ will exist no more.

Notes:

['] Modulació semàntica

[2] Modulació incrementativa lèxica.

${ }^{[3]}$ Literalitat lèxica

$++$

(1) Transposició.

(2) Modulació incrementativa sintàctica; variació en l'estil.

$\left(^{3}\right)$ Transposició.

$++$

I' Adaptació, per modulació sintàctica gencral, Variació en l'estil i en el punt de vista; hi ha la personificació de «the love».

R) Modulació semàntica.

B) Modulació semàntica, que determina una reducció de sentit quant a un element essencial en la retòrica poeticoamorosa d'Ausiàs March. Així, «ben amar» $>\langle$ lovc» -només-.

$++$

II $\Lambda$ daptació, per modulació sintàctica general. No hi ha la personificació que hi havia en $/ 1$ - vid. $\Lambda^{3} \longrightarrow$.

12) Modulació semàntica.

13) Esmena de $l^{3} \longmapsto$.

eixir a carrera loc. verb. Eixir a camí, a l'encontre d'algú.

Poema $11^{12}$

V. 9

$<O>\left[{ }^{1}\right]\left[{ }^{2}\left({ }^{1} \backslash^{1}\right.\right.$ Braços uberts $\left.)\right]\left({ }^{2}\right)\left[\left.^{3}\right|^{2} e ́ s\right.$ exid a carrera, 1$]$

$\langle\mathrm{TE}\rangle \quad$ ['Death] [ ${ }^{3}$ has come out into the street] ['with open arms,]

$<\mathrm{CO}>\quad$ (With open arms) ( ${ }^{2}$ she) $\left({ }^{3} s\right.$ come out in the street,)

<AR2> I'Death rushes out onto the road, I'with its arms outstretched

Notes:

['] Modulació incrementativa lèxica. Explicita el subjecte el-lidit a l'original,

$\left.{ }^{2}\right]$ Litcralitat lèxica, tot i que podem percebre una modulació sintàclica basada en l'increment de «with», a més a més de la transposició sintàctica que és la situació que ocupa respecte l'original.

[i] Modulació explicativa.

$++$

(1) Modulació sintàctica, basada en l'increment de «with». Hi ha un caire més explicatiu.

(2) Increment lèxic, que explicita el subjecte el-lidit de l'original.

11 Vid. els comentaris de Dilla, 1997 i Torres, 2000.

12 Vid. els comentaris de Di GIRolAMo, 1997: 376-377. 
$\left({ }^{3}\right)$ Modulació explicativa.

$++$

M Modulació semàntica, a mćs a més de la transposició sintàcica, que és la situació que ocupa respecte l'original. Podem percebre una variació certa variació de registre (almenys de mena diafasica), respecte a $\left.{ }^{2}\right]$. En aquest cas, torna a primar l'objectiu de voler ser més cxpressiu, com ara també en 127.

(2) Modulació explicativa, a més a més de la transposició sintàctica, que és la situació que ocupa respecte l'original. Podem percebre una variació certa variació de registre (almenys de mena diafassica), respecte a $\left.{ }^{2}\right]$. En aquest cas, torna a primar l'objectiu de voler ser més expressiu, com ara també en 12 .

encercar consell loc. verb. Demanar parer sobre un assumpte.

Poema $11^{13}$

V. 1

$<0>\left.\left|1^{2}\right|\left({ }^{1}\right)\right|^{3}$ Quins ['( ${ }^{2} \tan$ segurs $\left.)\right]\left[{ }^{2}\left({ }^{3}\right.\right.$ consells $)\left[{ }^{3}\left({ }^{4}\right.\right.$ vas encerquani,$\left.\left.i\right)\right]$

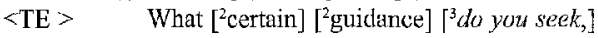

$\langle\mathrm{CO}\rangle \quad$ ('And) what ('so certain) ( ${ }^{3}$ counsel) ( ${ }^{4}$ do you seek,

$<$ AR2 $>\left.\quad \quad \quad\right|^{2}$ Wretched heart! I $I^{3}$ f what use would good advice be to you $\backslash$

Notes:

['] Modulació semàntica.

[2] Modulació explicativa lèxica, amb una certa variació de registre respecte a $\left(^{3}\right)$.

$\left[{ }^{3}\right]$ Literalitat lèxica.

$++$

(1) Modulació incrementativa lèxica, a fi de filar millor el discurs.

(2) Literalitat lèxica.

(3) Literalitat lèxica, amb una certa variació de registre respecte a $\left[^{2}\right]$.

( $\left.{ }^{4}\right)$ Litcralitat lèxica.

$++$

M Adaptació.

(2) Modulació incrementativa lèxica, derivada de una transposició interversal; derivada del «cor malastruc» amb que comença el vers següent.

(3) Adaptació.

errar cami loc. verb. Seguir una direcció incorrecta, materialment o moral.

Poema 6

V. 9

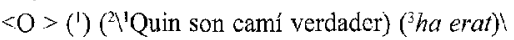

$\left\langle\mathrm{CO}>\right.$ ('Whoever) ('hath mistaken) ( ${ }^{3}$ this true way)

$<$ AR2> IOnce a traveller takes a wrong turn

Notes:

() Modulació incrementativa lèxica, que contribueix a fer més explicatiu el passatge.

(2) Transposició

(3) Literalitat lèxica, tot i que ací es perd el matís d'〈errança» que, sens dubtc, és latent en l'original - que juga amb l'ambivalència d'errar com a 'desencert' $i$, alhora, com allò que té de '(re)erca', semblant al que feicn els cavallers literaris (MARTEES,

13 Vid. els comentaris de DILLA, 1997. 
1995) -element essencial en el tipus de formació cortesana que rebia al segle XV l'estament al qual pertanyia Ausiàs March, qui no debades pertanyia a la mà militar $++$ de la societat valenciana del scu temps (CHINER, 1997 i 1999)—.

\Adaptació.

ser en tenebres loc. verb. Estar a les fosques, sense llum ni claror.

Poema $18^{14}$

V. 36

$<\mathrm{O}>\left[{ }^{1}\left({ }^{1}\left({ }^{2} \mathrm{e}\right.\right.\right.$ tant com $)\left[{ }^{2}\right]\left[{ }^{3} \mathrm{viu}\left({ }^{3} \mathrm{ab}\right.\right.$ ell $\left.)\right]\left[{ }^{4}\left({ }^{4} e^{2}\right.\right.$ en tenebres, $\left.)\right]$

$\langle\mathrm{TE}\rangle$ ['and as long as] [ ${ }^{2}$ the soul] [ [dwells in it,] [ ${ }^{4}$ it is in darkness),]

$<\mathrm{CO}>$ ('It dwells ( ${ }^{4}$ in darkness) ('e'er) it lives ('thcrein,))

$<$ AR2> I'and knows only darkness while it dwells within it

Notes:

['] Transposició, que determina una variació en l'estil i en el punt de vista del passatge.

$\left.{ }^{2}\right]$ Modulació sintàctica.

[3] Modulació sintàctica; hi podem percebre una certa variació de registre amb respecte a $\left({ }^{3}\right)$.

[4] Literalitat lèxica.

$++$

(1) Transposició, que đetermina una variació en l'estil i en el punt de vista del passatge.

(2) Modulació incrementativa lèxica, que explicita cl subjecte, a partir de la interpretació del traductor.

(3) Modulació sintàctica; hi podem percebre una certa variació de registre amb respecte a [3].

(4) Literalitat lèxica.

$++$

1) Adaptació. Això no obstant, hi ha clarament les dues paraules clau que transmeten els respectius nusos forts del sentit del vers i coincideixen amb les que concorren en $<\mathrm{TE}\rangle \mathrm{i}\langle\mathrm{CO}\rangle$ : «dwclls» $\mathrm{i}$ «darkness». Ara bé, a més a més de la transposició que hi observem, també hi ha l'influx de «knows», que expressa de manera més fàcilment «sabedora» el que conté el ver ser en «ćs cn tenebres» de l'original.

haver desacordança loc. verh. Discrepar.

Poema 34

V. 39

$<\mathrm{O}>\mathrm{e}$ ('los volers) $\left({ }^{2}\right.$ han $\left({ }^{3}\right.$ gran) desacordança:)

$<\mathrm{CO}>$ And ('base desires) ('have ('greatest) disaccordance:)

Notes:

(1) Modulació semàntica, quc cs basa en l'explicitació que els «volers» ausiasmarquians en són els «desitjos bàsics».

D'aquestu manera, els traductors estableixen una correspondència, potser en excés directa, entre «voler» $\mathrm{i}$ «desitjar» («love» $\mathrm{i}$ «desirc» - en els corresponents angle-

14 Vid. els comentaris de DiLı.A, 1997. 
sos--). En la tradició romànica medicval de base trobadoresca, aquesta correspodència no es donava; dc fct, hì havia una distinció ben clara entre el que erı el «desig» i «voler»-«estimar». Aquesta no diferenciació també és donava en la retòrica poètica medieval anglesa (i renaixentista-barroca); en gran mesura perquè es fonamentava sobre la poètica trobadoresca — arran dels «trouvers» i de la «importació» cultural que en va determinar la cort de l'Elionor d'Aquitània, reina consort i esposa llargament empresonada pel seu marit Enric II de plantagenet. més avant, en la poc̀tica isabelina, en el trenc dels ss. XVI-Xvil, potser les fites s'csvacixen un punt, tot $i$ que no s'hi arriba a la mistificació.

De tota mancra, si es tracta d'un original medieval i molt determinat, com ara ausiàs march - mal a son grat (vid. Poema xxm: «leixant a part l'estil dels trobadors»)-, per la poètica trobadoresca - la qual conformava el «disseny curricular» de qualsevol lletraferit de l'època-, convindria, més ainna, no cometre aquesta correspondència (biblingrafia).

( $\left.{ }^{2}\right)$ Modulació semàntica, qu estableix un to més intensiu de $\left({ }^{3}\right)$.

$\left({ }^{3}\right)$ Modulació incrementativa semàntica.

haver en desheret loc. verb. Menystenir, tenir en poc valor — vid. infra. nota $\left({ }^{2}\right)$ corresponent a aquest cas.

Poema 53

V. 17

$<0>/ 1$ Tan gran amor ${ }^{2}$ haurian deserets $\Lambda$

$<\mathrm{AR}>/ 1 \backslash^{2} I$ would be betraying such! great love/

$<$ AR2> \'If I were to allow such a matter as this to pass!

\section{Poema 53}

V. 18

$<O>\beta \backslash 2$ que tal affer menys de senyal passàs. $\Lambda$

$\left.\langle\Lambda R\rangle \quad \beta^{\beta}\right\rangle^{2}$ as mine if $\mathrm{I}$ were to allow such a matter to pass unnoticed $\rangle$

$\angle A R 2>1^{2} T$ would betray the greatest of loves.

Notes:

1i. Transposició.

2f Modulació semàntica, que proposa una interpretació que fa sentit, tot i que es tracta d'un vers que tampoc no resta totalment aclarit en l'original.

Bohigas ( ${ }^{2} 000: 522 \mathrm{~b}$ ), en el «Clossari», que tan esbandidor de dubtes resulta en molts casos, ja indica que «deseret» es tracta d'un terme boirós: «deseret: Lirt, 17, abandó (?)». Bohigas (2000: 190) mateix ens glossa el sentit d'aquest vers i el següent («Tan gran amor hauria'n deserets / que tal affer menys de scnyal passàs» [LiI, 17-18]): "Consideraria fracassat el seu amor si no cs manifestava amb senyals visibles. Els dos versos que segucixen corroboren aquest pensamenty. ${ }^{15}$

Si tenim present aquesta nota i les diverses accepcions del nucli de la unitat de traducció corresponent (ubetraying»), podrem inferir que el sentit l'original deu girar a l'entorn de la noció que 'un amor sense elements visibles, és a dir, sense proves o «béns tangibles», resultaria un amor que no fa fermança de la seua validesa, que es troba «privat» 0 «desprovist».

15 Vid. aqueixos versos i tot cl Poema Lul, m en l'edició interlinial, en açuest mateix treball. 
En aquest sentit, trobarem fonaments en el que $\Lambda$ rcher ens indica en la seua edició de l'original (ARCHER (ed.), 1997: 1, 223 [nota a LII, 17]): «ho consideratia un desheretament, és a dir, una injustícia.\%

Sobrc la base del 'desheretament', potser convindrà tenir compte la traducció d'Ausiàs March al francés feta per Gilreu. Aquest filòleg tradueix aquest vers: «D’un si grand amour serais déshéritém. En Le Gran Robert (2001'2; 1353a), s.v. déshériter, llcgim:

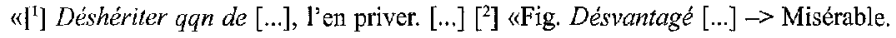
[...] Déshérité de qqch $\rightarrow$ Frusté, privé.»

2f Adaptació.

$++$

il Transposició $\mathrm{i}$ adaptació interversal 12 .

(2) Transposició i adaptació interversal $\$.

\subsection{Col-locacions}

fin amador col. En la tradició poètica trobadoresca, el qui ama amb molta intensitat d'acord amb les regles de la cortesia.

Poema 63

V. 17

$<\mathrm{O}>\left[{ }^{\mathrm{L}}\left(\left[{ }^{2}\right.\right.\right.$ Dolor és gran] de tot fin amador, $)$

$\langle\mathrm{IE}\rangle \quad$ ['Every the lover ['suffers greatly]]

$\langle\mathrm{CO}\rangle$ ('Great is the pain of every Lover true,

Notes:

['] Transposició.

['] Adaptació sintàctica, canvi d'estil.

$++$

(1) Literalitat lèxica.

béns movents col. Pertinences que es poden moure o transporar.

Poema $31^{16}$

V. 36

$\angle \mathrm{O}>$ ('los béns movents e los sients arrasa)

$\langle\mathrm{CO}\rangle$ ('Goods movable and mar those sedentary;)

Notes:

(1) Literalitat Tèxica.

béns sients col. Pertinences immobles. Vid. béns movents col.

ben amar col. Amor cortés. Vid donar terme loc. verb.

mal astre. Dissortat, mal fadat.

Poema $76^{17}$

V. 30

$<\mathrm{O}>$ ('lexant lo cors desastruch per mal asire;)

$<\mathrm{CO}>$ (Abandoning the body ill-starred and doomed;)

16 Vid. els comentaris de KEOWN, 1999: 209.

17 Vid' els comentaris de DiLla, 1997. 
Notes:

(') Literalitat lèxica.

mal grat col. Desgrat.

Poema $25^{18}$

V. 38

$<\mathrm{O}>$ (' mal grat haureu del que fćs un matí.)

$<\mathrm{CO}>$ ('You will repent for that you did one mom.)

Notes:

(1) Litcralitat lèxica.

tancar camí col. Impedir o dificultar les possibilitats d'actuació a algú; no donar possibilitats.

Poema $89^{12}$

V. 8

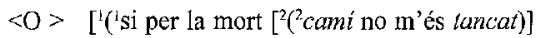

$<\mathrm{TE}\rangle\left[{ }^{1}\right.$ if the [ ${ }^{2} \mathrm{road}$ is not closed to me] by death.]

$\langle\mathrm{CO}\rangle$ ('Unless by Death ('to me the path is closed.)

Notes:

[1] Transposició.

$\left.{ }^{2}\right]$ Modulació lèxica, derivada de la transposició [']; podem percedre una certa variació cn el registre respecte a $\left({ }^{2}\right)$.

$++$

(1) Transposició.

$\left({ }^{2}\right)$ Modulació lèxica, derivada de la transposició $\left({ }^{1}\right)$; podem percedre una certa variació en el registre respecte a $\left[{ }^{2}\right]$.

taula mesa col. Taula parada, quan tot és llest o fàcil.

Poema 16

V. 23

$<0>$ (1tots entraran, sients a taula mesa:)

$\angle C O>$ ('They all will enter, set themselves at tabie:)

Notes:

(') Literalitat lèxica.

sentir prim col. Bon enteniment, trellat, bon judici.

Poema 33

V. 12

$\angle 0>$ ('ab sentir prim, qui desperta desdeny.)

$<\mathrm{CO}>$ ('With subtle feeling which disdain doth rouse.)

Notes:

(1) Litcralitat lèxica.

18 Vid. els comentaris de Di Girolamo, $1997 \mathrm{~b}$.

19 Vid. els comentaris de DiLLA, 1997. 
dol e plant col. Aflicció molt intensa.

Poema 99

V. 50

$<\mathrm{O}>$ ('per colpa gran) ('me dónì dol e plant.)

$\langle\mathrm{CO}\rangle$ ("Who through her fault brings ( ${ }^{2} \mathrm{me}$ to mourn and plaint.)

Notes:

(1) Modulació sintàctica, amb reducció semàntica: «colpa gran» > «through her faults».

(2) Literalitat lèxica.

\section{Conclusions}

El contrast de les traduccions amb els originals constitueix una magnífica ocasió per a l'estudi de la recepció d'una obra i, a partir d'aci, dels mecanismes que n'han guiat o determinat la creació (VlLLANuEva, 1994). Qui subscriu ha pretés oferir una visió global de la transmissió de les obres a través de les seues versions i les opinions que cadascuna d'elles ha generat en la crítica pel que fa a Ausiàs March.

Per una altra banda - i això pot ser més interessant-, aquest estudi intenta tenir en compte els tres aspectes de l'anomenada comunicació literària establerta a l'entorn de les obres de March i de les seues versions o traduccions, i, també, a l'inrevés, és a dir, de les versions en català o en aragonés d'obres originalment escrites en altres llengües.

Aquesta tasca té el propòsit de parar esment en l'abast que van tenir les obres originàriament escrites en la Corona Catalanoaragonesa, en català, a través de les seues versions en altres llengües. Així hem pogut analitzar la importància de realitzar un acarament entre els textos (o versions) originals i les traduccions. Això no sols ens aportarà informació de tipus historicoliterari, sinó que també resultarà de gran interés per a qüestions de Traductologia $i$ des del punt de vista de la Història de la Llengua (WitTlin, 1995; MARTines, 2001).

El cas de la versió bíblica de Casiodoro de Reina ens evidencia un altre cas de cadència, innovació cultural i encert en els criteris lingüístics aplicats. Ens sembla ben definidor el que ens en diu Luis Manuel Ruiz (2002: 48d):

"Fstamos acostumbrados a que el Espíritu Santo se exprese cn un lenguaje ceniciento y monótono, que se resigne a la pobreza de los artículos jurídicos. Cuando se abre el texto de Reina en cualquier página, el lector es acariciado por la soberbia cadencia de la prosia, y entiende que por primera vez los intérpretes han hecho justicia al estilo de una divinidad. Casiodoro compuso este monumento desconocido de nuestro idioma durante 10 largos años en que sufrió el exilio, la acusación de herejiá, la persecución de las autoridades eclesiásticas: verter la palabra de Dios a una lengua vernácula era un delito mucho mayor que matar en su nombrc. El olvido enterró ecuánimamente al autor y a la obra años más tarde de la publicación; fuc un correligionario de Reina, Cipriano de Valera, perteneciente como a ćl a la Orden de los Jerónimos Observantes, quién logró resucitarla con ayuda de un prólogo y notas, en 1602. Desde entonces, hace hoy 400 años, Dios maneja un excelente castellano.»

Això, posar en pràctica el cabal d'informacions de la traducció i la traductologia per a la docència de la literatura i la llengua pot ser molt beneficiós. Els alumnes podran comprovar 
no solament el grau de fidelitat de les traduccions, sinó també - i sobretot- en què modifiquen l'original i de quina manera ho fan.

En establir les concordances, els llistats de mots i les lematizacions, de les traduccions del nostre poeta i en analitzar en concret la praxi traductològica dels seus traductors anglesos hem pogut fornir eines per a l'estudi del lleguatge poètic ausiasmarquià. En $\mathrm{cl}$ status quaestionis dels estudis sobre March podem comprovar que, després dels comentaris de poemes, les traduccion són un dels ítems que més nombre d'atencions ha tingut per part de la crítica. Ara bé, convé combinar l'estudi del lèxic de l'original amb l'anàlisi de les correspondències en altres llengües que n'han fet traductors solvents i filòlegs, sovint com a crossa per a. la seua pròpia comprensió de l'original.

Si centrem la notra atenció en les locucions, les collocacions i els modismes podrem atendre tres lingüístics d'una gran incidència en la caracterització del llenguatge poètic d'Ausiàs March i, per tant, poden tenir una intensa - potser que fins i tot tensa- influència en los de traduir que han de formar part de l'estratègia traductològica, precisament perquè poden ser elements que indiviuen ja l'original. Aquests elements són essencials per entendre la construcció d'un text, sia des de la perspectiva de l'anàlisi del discurs original, sia des de la perspectiva traductològica específicament. Hi ha, altrament, interés des del punt de vista de la diversa activació dels procediments de metaforització. Per tot això són veritables «unitats crítiques» de traducció que determinen haver de realitzar transposicions, modulacions, equivalències $o$ adaptacions.

Les coordenades essencials de les tècniques que segueixen aquests traductors en la traducció d'Ausiàs March: transposicions (sovint abruptes); modulacions semàntiques i sintàctiques (sovint incrementatives i molt poques vegades reduccionistes) que tendeixen a conferir, en general, un to mćs intensiu a la traducció; tria lèxica i la texlura morfosintàctica que tendeix a ser més arcaïtzant que les de Terry o la d'Archer.

D'altra banda, Conejero-Ribes-Conejero plantejen una concepció més «traductològica», menys crossa i més autònoma, tot i que això implosa més d'un peatge i necessitaria en més d'un moment un giatge més estret perquè el lector no es desorienlés. De fet, Conejero-RibesKeown volen «metre» Ausiàs March en «English verse». De fet, aquesta traducció és molt fidel i equivalent a l'original, i això és un mèrit d'aquests traductors. Aquesta versió és força «centripeta». Ens pot remetre a la lírica isabelina anglesa (ss. xvi-xvi) i no és desgavellat dir-ne que vol encabir-se en un solc «shakesperarià». Això és lícit en traducció $i$ ho fan així perquè pot ser un refercnt equiparable en l'àmbit cultural i líric anglés al que representa Ausiàs March en el català, hispànic i romànic. Aixó, però, imposa que els seues «lectors (anglesos) hagen de saber molt d'anglés»).

La traducció de Terry és centrífuga, vol ser un Mercuri que transmeta el text d'Ausiàs March. Alhora, no perd mai de vista l'original i només en molt comptades avinenteses podem dir que arribe a «cometre» adaptació -i menys encara adaptació per inintel·lecció-. Dc fet, quan ha de fer modulacions incrementatives lèxiques $i$ afig o intepola mots -0 poques voltes sintagmes-, ho consigna entre parèntesis.

Archer també aborda la seua traducció amb una perspectiva centrífuga tot i que més que no Terry; d'altra banda, Archer se situa en l'extrem oposat a Conejero-Ribes-Keown. De fet, la seua traducció, així com també la de Terry, és en prosa, tot i que es fàcil de fer-ne la correspondència amb l'estructura versal de l'original. La mateixa estratègia ha estat en la base de la nova traducció de poemes d'Ausiàs March que ha acabat Archer, encara inèdita. 
En els exemples acarats - dels quals ara i ací només mostrem una petítissima part, ateses les limitacions d'espai de la publicació - hem trobat nombrosos elements per precisament, caracteritzar amb detall aqueixes traduccions $i$, alhora, la manera en què han entés i rebut els traductors els textos ausiasmarquians. No deixa de ser simptomàtic que sovint trobem aqquesta tècnica. Diu molt en favor de l'ofici d'aquests traductors, tots ells -especialment Terry, Keown i Archer, i també Wittlin quant al poema 28 -- filòlegs de reconeguda solvència internacional en l'àmbit de la literatura catalana medieval.

Tinguem present que hom entén per traducció literal quan hi ha l'adequació completa del text traduït al text d'origen. Es dóna quan tant el contingut com l'expressió són rèpliques que es corresponen ben bé amb l'original en els diversos nivells (semàntic, morfològic, sintàctic i -afegim-conceptual).

Tampoc no deixa de ser de ser simptomàtic quant a les transposicions, i a desgrat del que hem dit quant a l'abundor do casos de literalitat lèxica, que hi haja en aquestes traduccions angleses nombrosos casos de transposicions. De fet es tracta d'una tècnica aquesta que ja pot formar part de l'»equipament de sèric» dels diversos objectius i criteris que ja hem vist segueixen cls traductors de referència. Això no obstant, hi ha diversos graus de transposició entre aquestes traduccions, precisament, en funció dcls seus respectius criteris. Així, tenim que no són tan nombroses en Conejero-Ribes-Keown, més centrípeta, com sí en Terry que vol ser centrífuga. Ara bé, en la d'Archer és on les transposicions tenen més incidència; tanta que sovint trobem adaptacions.

En general --com assenyalem on s'escau- les transposicions que hem observat bàsicament tenen un abast de dos tipus: intraversal (sintagmàtic, en definitiva), o interversal. Altrament, les transposicions sovint determinen un canvi d'estil (canvi de tipologia sintàctica) i/o un canvi en el punt de vista atés que el traductor interpreta en cada cas que potser convé intensificar - el més sovint - o matisar el to del passatge. Potser per tot això plegat, la modulació és el procediment de traducció més usual en aquestes traduccions. De fet ben bé podem dir que és lògic, això, en qualsevol tasca traductològica. Entre la diversa tipologia dc modulacions, les que trobem en les nostres anàlisis - i el lector pot comprovar tot seguit així com també el l'edició interinial一, són:

- Modulació incrementaliva (semàntica, lèxica o sintàctica): els nostres traductors tenen un afany comú, a desgrat dels objectius i criteris traductològics diversos que ja hem vist que expliciten: aclarir i fer significatius per als lectors els trets poètics (Conejero-Ribes-Keown) o semàntics (Terry i Archer) de l'original. Això, ho duen a terme en afegir mots - quc Terry posa entre parèntesis - o fins i tot sintagmes que o bé aclareixen matisos, o bé expliciten subjectes o referents sintàctics el-lidits o sobrentesos per l'original, o bé intensifiquen el to del passatge.

- Modulació explicativa: en relació amb l'anterior i amb les transposicions, ens trobem casos en què els traductors modifiquen la perspectiva oracional en traslladar el català amb cxplicacions o glosses. Aquest recurs es dóna sovint en Archer $i$ sovint frega l'adaptació.

En definitiva creiem assolit un dels objectius que ems proposàvem a l'inici d'aquest treball. Ara podem fer nostres els mots del mestre Martí de Riquer quant a les traduccions castcllanes d'Ausiàs March en «la Edad de Oro» i amb les quals obríem el nostre estudi. 


\section{REFERĖNCIES BIBLIOGRÁFIQUUES:}

Amossy, Ruth (2001): «D'une culture à l'autre: réflections sur la transposition des clichés et des stéréotypcs», Palimpsestes, 13.

Antoine, Fabrice (2001): «Le dictionnaire bilingue, conservatoire de clichés», Palimpsestes, 13 (2001).

Archer, Robert, ed. (1997), Ausiàs March, Obra completa, 2 vols., Barcelona, Barcanova.

Archer, Robert, trad. (1992), Ausiàs MArch. A Key Anthology, Sheffield, The Anglo-Catalan Society.

Archer, Robert, trad. (2004 [en premsa]), Ausiàs Marck. A New Translation, Alacant-Durham (UK), Xarxa d'Excel-lència Europea "TRAMICTEK» -'Translation, Multilingualism, Information and Communication Technologies and Transference of Knowledge'-.

Arrimadas Saavedra, Jesús (1987): «La traducción, fuente de la paremiologia francesa de los siglos XII-XVI», dins Julio Cesar Santoyo, Rosa Rabadán, Trinidad Guzmán \& Josć Luis Chamosa (eds.), «Fidus interpretes»: Actas I Jornadas Nacionales de Historia de la Traducción, Lleó, Universidad de León, pp. 290-298.

Baker, Mona (1992): In Other Words: A Coursebook on Translation, Londres, Routledge.

Barbolani di Montauto, Maria Cristina (1997), «Los refranes en una traduction renacentista (españolitaliano)», Paremia, 6.

Bcckman, John (1968): «Eliciting vocabulary, meaning, and collocations», Notes on Translations, 1, 29.

Behiels, Licve (1993): «Cómo se tradujeron los proverbios de La Celestina cn neerlandés y alemán», Paremia, 2.

Bennett, John A. (1994): «Colour Collocations in Prospectus and Advertising Material», $T \& T, 2$, pp. $123-132$.

Bohigas, Pere, ed. (2000), Ausiàs March, Poesies, edició revisada per Amadeu-J. Soberanas \& Noemí Espinàs, «Pròleg» de Lola Badia i «Bibliografia ausiasmarquiana» de Joan Santanach \& Vicent Martines, Barcelona, Barcino ( $(\mathrm{ENC}), 18$, colleceió B).

Butterworth, Charles E. (1994), "Translation and Philosophy: The Case of Averroes' Commentaries», International Journal of Middle East Siudies, 26, 1, pp. 19-35.

Cantera Ortiz de Urbina, Jesús (2000): «Locuciones, giros y modismos del español y su correspondencia en francés», dins Gloria Corpas Pastor (ed.), Las lenguas de Europa: Estudios de fraseología y traducción, Granada, Comares, pp. 431-454.

Cátedra, Pedro M., (2002), «Enrique de Villena», dins Carlos Alvar \& José Manuel Lucía Megias, Dicionario Filológico de Literatura Medieval Española. Textos y transmission, Madrid, Castalia.

Cátedra, Pedro M., ed. (1994-2001), Enrique de Villena, Obras completas, 3 vols., Madrid, Tumer.

Chiner Gimeno, Jaume (1997), Ausiàs March i la València del segle XV (1400-1459), València, Consell Valencià de Cultura (Generalitat Valenciana).

Chiner (Gimeno, Jaume (1999c), «'En vós està fer son cas fort o floch'. Corrcccions d'autor a Ausiàs March i la València del segle XV (1400-1459)), Llengua \& Literatura, 10.

Combet, I ouis \& Julia Sevilla Muñoz -col lab: Martín Navajo Calvo- (1995): «Proverbes, expressions proverbiales, sentences et lieux communs sentencieux de la langue française d'aujourd'hui, avec leur correspondance espagnole», Paremia, 4.

Conejero, M. A., Purificación Ribes \& Dominic Keown, trads. (1997-2001), Ausiàs March. Selección de poemas / Selected Poems, València, Instituto Shakespearc Fundación.

Copeland, Rita (19952 [1991]), Rhetoric, Hermeneutics, and Translation in the Middle Ages: Academic Traditions and Vernacular Texts, Cambridge, Cambridge University Press.

Coronel Ramos, Marco Antonio (2000), «Ausiàs March recréé en lalin par l'humaniste Vicente Mariner", dins Georges Martin \& Marie Claire Zimmermann (eds.), Ausiàs March (1400-1459), premier poète catalán, París, Cahiers dc Linguistique Iispanique Médiéval / Klincksieck, pàgs. 339-344. 
Coronel, Marco Antonio, ed. (1997a), La traducción latina en verso de la obra completa de Ausiàs March, realizada por el valenciano Vicente Mariner (Turnoni, 1633), València, Universitat de València. [Tesi doctoral, edició en microforma.]

Coronel, Marco Antonio, ed. (1997b), L'Ausiàs March llatí de l'kumanista Vicent Mariner, «Pròleg» de Germà Colón, València, Edicions Alfơns el Magnànim / Intitució Valenciana d’Estudis i Invcstigacions / Gencralitat Valenciana / Dipulació Provincial de València.

Corpas Pastor, Gloria, ed. (2000); Las lenguas de Europa: Estudios de fraseologia y traducción, Granada, Comares.

Cranz, F. Edward \& Paul O. Kristeller (1976-1980), Catalogus translationum et commentariorum. Mediaeval and Renaissance Latin Translations and Commentaries. Annotated Lists and Guides, Washington, Catholic University of America Press.

Cuenca, Maria Josep (2000): «L'estudi de les costruccions idiomàtiques des de la lingüística cognitiva i l'anàlisi contrastiva», dins Vicent Salvador \& Adolf Piquer (eds.), El discurs prefabricat: estudis de fraseologia teòrica $i$ aplicada, Castclló, Universitat Jaume I, pp. 33-48.

Di Girolamo, Costanzo (1997), «Tradurre Ausiàs March», Llengua \& Literatura, 9, pp. 369-390.

Di Girolamo, Costanzo (1997c), «Tradurre Ausiàs March», Llengua \& Literatura, 9, pp. 369-390.

Dilla, Xavier, ed. (1997), Guia de lectura d'Ausiàs March, Barcelona.

Dobrovl'skij, Dimitrij (1990 [1992]): «Phraseological Theasures in the Process of Translation», dins Barbara Lcwandowska-Tomaszczyk \& Marcel Thelen (eds.), Translation and Meaning, 2: Proceedings of the Lodz Session of the 1990 Marstricht-Lodz Duo Colloquium on "Translation and Meaning», Maastricht, Euroterm, pp. 35-42.

Fabregat, Ferran (1997): «Aproximació cognitiva a la traducció de les expressions idionàtiques», dins Montserrat Bacardí (ed.), Actes del II Congrés Internacional sobre Traducció (abri, 1994), Bellaterra, Universitat Autơnoma de Barcclona, pp. 505-516.

Fawcett, Peter (1997), Translation and Language. Linguistic Theories Explained, Manchester, St. Jerome.

Fernández González, Jesús (1995): «Algunas reflexiones sobre aspectos gramaticales e interlingä́íti$\cos$ de las expresiones idiomáticas», dins Carlos Hernández Sacristán, Brigitte Lépinette \& Manuel Pérez Saldaña (eds.), Apectes de la reflexió i de la praxi interlinguiistica, València, Universitat de València, pp. 231-246.

Fontencllc, Thierry (1994): «Towards the Construction of a Collocational Database for Translation Students», Meta, 39, $1<$ http://www.eruditorg/revue/meta/>

Fraile Vicente, Esther (2001): «Estrategias para la traducción de las connotaciones latentes en los binomios irreversibles idiomáticos de la lengua inglesa y las expresiones idiomáticas en general», $T \& T, 3$, pp. 101-143.

Fuertes Olivera, Pedro A. \& Eva Samanicgo Fernández (1998): «Metaphor and Motivation: A Study of English Informal Phraseological Units», Lexicology, 4, 1, pp. 35-59.

García Gabaldón, Jesús (1996), «Sobre el Comparatismo Lingüístico y Literario», Teoria/Crítica [Monográfico: Ciencias del lenguaje y de las lenguas naturales, a cura de M. Helena Fcrnández Prat), 3, pp. 113-127.

García Izquicrdo, Isabel (2000): «Reflexions a l'entorn de la traducció (al català i a l'espanyol) d'algunes unitats fraseològiques de Three Men in a Boat», dins Vicent Salvador \& Adolf Piquer (cds.), El discurs prefabricat: estudis de fraseologia teorica i aplicada, Castelló, Universitat Jaume I, pp. 153-167.

Gargallo Gil, José Enrique (2002), «Per Santa Llicia, un pas de puça. Crecer y decrecer de los días, refranes del calendario, Romania continua», Estudis Romàmics, 24, pp. 109-137.

Génin, Isabelle (2001): «Des métaphores pas si mortes. Redynamisalion des métaphores fingées dans Moby-Dick et ses traductions françaises), Palimpsestes, 13.

Heliel, Mohamed Helmy (1990); «Lcxical Collocations and Translation», dins Marcel Thelen \& Barbara Lewandowska-Tomaszczyk (eds.), Translation and Meaning, Maastricht, Hogeschool Zuyd / Maastricht School of Translation and Interpreting, pp. 129-139. 
Hjornager, Viggo (1985 [1986]): «The Translation of Collocations and Idioms», dins Lars Wollin \& Hans Lindquist (eds.), Translation Studies in Scandinavia. Proceedings from the Scandinavian Symposium on Translation Theory (SSOTT) II (Lund 14th and 15th June, 1985), Lund, Wallin \& Dalholm Boktryckeri, pp. 126-132.

Hosington, Brenda B. (1993 [1996]): «Proverb Translation as Linguistic and Cultural Transfer in Some Middle Versions of Old French Romances», dins Roger Ellis \& René Tixier (eds.), The Medieval Translation, 5. Traduire au Moyen Age, 5, Turnhout (Bèlgica), Brepols, pp. 170-186.

Kelly, Louis G. (1990), «Medieval Philosophers and Translation», dins Hans Joscf Niederehe \& Konrad Koerner (eds.), History and Historiography of Linguistics: Papers from the Fourth International Conference on the History of the Language Sciences (ICHoLS IV), Trier, 24-28 August 1987, 2 vols., Amsterdam, Benjamins, pp. 399-873.

Kenny, Dorothy (2000), «Lexical Hide-and-Seck: Looking for Creativity in a Parallel Corpus», Maeve Olohan (ed.), Intercultural Faulties. Research Models in Translation Studies I: Textual and Cognitive Aspects, Manchester, St. Jerome.

Kenny, Dorothy (2001), Lexis and Creativity in Translation. A Corpus-based Study, Manchester St. Jerome.

Keown, Dominique (1999), «Algunes reflexions sobre la traducció d'Ausiàs March a l'anglés», dins Vicent Martines (ed.), Canelobre. Estudis sobre Ausiàs March, 39-40, pàgs. 201-28.

Lozano González, Wenceslao Carlos (1992): «Aproximación al problema de las expresiones idiomáticas y su traducción», Sendebar, 3.

Malmkjaer, Kirsten (1993): "Who Can Makc 'Nice' a Better Word than 'Pretty"? - Collocations, Translation and Psycholinguistics», dins Mona Baker, Gill Francis \& Elena Tognini-Bonelii (eds.), Text and Technology: In Honour of John Sinclair, Amsterdam, John Benjamins.

Martines, Vicent (1995), «La versió calalana de la Queste del Saint Grasal i l'original francés», dins Juan Paredes Núniez (ed.), Medioevo i literatura. Actas del V Congreso de la Asociación Huspánica de Literatura Medieval (Granda, 1993), Granada, Universidad, pp. pp. 241-252.

Martines, Vicent (1996), «Tiempo y espacio en la versión catalana de la Queste del Saint Graab), Hispanic Review (Pennsylvania, EUA), 43, 3, 373-390.

Martines, Vicent (1997), El «Tirant» poliglota. Estudi sobredel «Tirant lo Blanch» a partir de les seues iratuccions espanjola, italiana i francesa dels segles XVI-XVIII, "Pròleg» d'Amadeu-J. Soberanas, Barcelona, Publicacions de l'Abadia de Montserrat / Curial Edicions Catalames.

Martines, Vicent (2001), «Traduccions, recepcions i transformacions; traduccions en la i de la literatura catalana medieval. Relacions d'anada $i$ tomada de literatura romànicas, a cura d'August Bover i Font, Maria Rosa Lloret i Mercè Vidal-Tibbits (eds.), Actes del Novè Colloqui d'Estudis Catalans a Nord-Amèrica (Institu d'Estudis Catalans, Barcelona, 1998), Barcelona, Publicacions de l'Abadia de Montserrat, pàgs. 245-268.

Mayoralas, José (2000): «Sinonimia semántica en estructura profunda de algunos clichés españoles y franceses», Babel, 46, 2, pp. 125-153.

Mitja, Violeta (1989): Las locuciones francesas en el campo semántico de la comida y su traducción al español, Madrid, Universidad Complutense de Madrid [Tesis].

Moeschler, Jacques (1991 [1992]): «Idiomes et locutions verbales: à propos de quelques bizarreries syntaxiques et mystères sémantiques», $T \& T, 2-3, \mathrm{pp} .135-148$.

Nadal, Joaquim \& Modest Prats (1982-1996), Història de la llengua catalana, 2 vols., Barcelona, Edicions 62.

Navarro Domínguez, Fernando (1995 [1996]): «Analyse du discours et proverbes détournés: un problème de traductions, dins Marcel Thelen \& Barbara Lewandowska-Tomaszezyk (eds.), Translation and Meaning, Maastricht, Hogeschool Zuyd / Maastricht School of Translation and Interpreting.

Nikoláeva, Julia (1997): «Lo traducible e intraducible en las paremias (análisis de refraneros españoles italianos y rusos», Paremia, 6. 
Núñez García, Laureano (1999): «El diablo en fraseologismos italianos y españoles; accrcamiento a un análisis cultural contrastivom, Paremia, 8.

Ojanguren Fernández, Ana (1995 [1997]): «Las versiones alemanas de las paremias pronunciadas por Sancho Panza en la II Parte del Quijote», dins Miguel Ángel Vega (ed.), La palabra vertida: imestigaciones en tomo a la traducción. Actas de los VI Encuentros Complutenses en torno a la Traducción, Madrid, Universidad Complutense, pp. 641-648.

Pavel, Silvia (1995): «Bibliographie de la phraséologie», Meta, 40, $4<$ http://www.erudit.org/revue' meta/s

Peters, H. (1992): «Lexicografia traduccional en la colocación de adjetivos», dins Gerd Wotjak (eds.), Estudios de lexicografia y metalexicografia del español actual, Tubinga, Max Niemeyer.

Pujol, Josep (1997), «Amor i desmemòria. Notes per a la interpretació del poema x d'Ausiàs March», dins Rafael Alemany (ed.) 1997, pàgs. 297-320.

Riino, Timo \& Lauri Juhani Eerikäinen (1993), Crestomatía iberomrománica. Textos paralelos de los siglos XIII-XVI, Helsinki, Annales Academiae Scientiarum Fennicae, ser. B. tom. 268.

Riqucr, Martín de, ed. (1946), Las traducciones castellanas de Ausias March, Barcelona, Instituto Español de Estudios Mediterráneos.

Ruiz, Luis Manuel (14-08-2002), «La Biblia», El Pais, p. 48d.

Salvador, Vicent \& Adolf Piquer (eds.) (2000): El discurs prefabricat: estudis de fraseologia teòrica i aplicada, Castelló, Universitat Jaume I.

Shoaf, R.A. (1997), «Literary Theory, Medieval Studies, and the Crisis of Difference», Reorientations, 56 , pp. 76-92.

Torres, Milagros (2000), «Tcatralidad y poeticidad en la poesia de Ausiàs March: la catarsis en e1 poema xiii», dins Georges Martin \& Marie Claire Zimmermann (eds.) 2000, pàgs. 297-306.

Villanueva, D. (1994), Curso de teoria de la literatura, Madrid, Taurus.

Vintar, Spela (2001), «Using Parallel Corpora for Translation-Oriented Term Extraction», Babel, 47, 2, pp. 121-132.

Wilss, Wolfram (1997): «Adjektiv / Substantiv -Kollokationen. Ein Beitrag zum Verständnis von Textaustein), dins Nadja Grbic \& Michaela Wolf (eds.), Text-Kultur-Kommunikation. Tranalation als Forshungsaufgabe, Tubinga, Stauffenburg, pp. 67-84.

Wittlin, Curt (1995), De la traducció literal a la creació literària, València/Barcelona, Institut Interuniversitari de Filologia Valenciana / Publicacions de l'Abadia de Montserrat.

Wittlin, Curt (1999), «Ausiàs March en anglés, amb una versió rítmica del poema XXVIII: 'Lo jom ha por...'», dins Vicent Martines (ed.), Canelobre. Estudis sobre Ausiàs March, 39-40, pàgs.223232.

Zimmermann, Marie-Claire (1997), «El poema LXXxı d'Ausiàs March: d'un tòpic revisitat a un metallenguatge», dins Rafael Alemany (ed.) 1997, pàgs. 355-364. 